\title{
Oxygen depletion during sapropel deposition: Reassessing redox proxies for reconstructing surface and bottom water oxygen conditions
}

\author{
MR. RICARDO DAVID MONEDERO-CONTRERAS, PHD \\ STUDENT $^{1}$, FRANCISCA MARTINEZ-RUIZ ${ }^{1}$, FRANCISCO \\ J. RODRÍGUEZ-TOVAR ${ }^{2}$, DAVID GALLEGO-TORRES ${ }^{3}$ \\ AND GERT J. DE LANGE ${ }^{4}$ \\ ${ }^{1}$ Instituto Andaluz de Ciencias de la Tierra (CSIC-UGR) \\ ${ }^{2}$ Universidad de Granada \\ ${ }^{3}$ European Research Council Executive Agency (ERCEA) \\ ${ }^{4}$ Dept Earth Sciences, Faculty of Geosciences, Utrecht Univ., \\ NL, and Key-Lab. Marine Geology \\ Presenting Author: ricardo.monedero@csic.es
}

The cyclical deposition of organic-rich sediments, so-called sapropels, in the Eastern Mediterranean represents a unique record for assessing causes and consequences of oxygen depletion in the past. Sapropels have been linked to periods of precessional minima that caused strengthening of the African monsoon, which increased river water runoff and that in turn resulted in increasing nutrient input and enhanced productivity in the Mediterranean Basin. Freshwater input also led to watercolumn stratification during certain periods, inhibiting deepwater renewal, which also boosted the preservation of organic matter. To further understand the evolution of surface and bottom water oxygen conditions during sapropel deposition and preservation, a multiproxy approach, including diverse geochemical and ichnological proxies has been performed. Sapropels intervals from ODP Leg 160 Site 964 (Ionian Basin) have been selected to provide new insights into the development of oxygen conditions over the last $3 \mathrm{Ma}$. Previous studies of the sapropel layers at this site have provided diverse reconstructions in terms of palaeoceanographic parameters, including productivity (i.e. $\mathrm{Ba} / \mathrm{Al}$ and $\mathrm{TOC}$ ) and oxygen conditions. In this study, we have reassessed some redox proxies previously used and also present additional ones (i.e. degree of pyritization DOPt- and enrichment factors) calibrated for this particular basin. These proxies provide detailed information of the evolution of paleo oxygen-depletion events in the Ionian Basin, allowing to reassess some previous interpretations. Moreover, ichnological interpretation of meiofauna traces is also integrated for a further understanding of the responses of the trace maker community to these depleted oxygen environments. In this matter, reconstructing past variations in oxygen conditions is of particular interest to further understand seawater deoxygenation and the marine environment in future scenarios. 